This is an Open Access article, distributed under the terms of the Creative Commons Attribution licence (http://creativecommons.org/licenses/by/4.o/), which permits unrestricted re-use, distribution, and reproduction in any medium, provided the original work is properly cited.

doi:10.1017/So144686X17001477

\title{
Seeing the collective: family arrangements for care at home for older people with dementia
}

\author{
CHRISTINE CECI*, HOLLY SYMONDS BROWN* and \\ MARY ELLEN PURKIS†
}

\begin{abstract}
With the predicted growth in the number of people with dementia living at home across the globe, the need for home-based care is expected to increase. As such, it will be primarily family carers who will provide this crucial support to family members. Designing appropriate support for family carers is thus essential to minimise risks to their health, to prevent premature institutionalisation or poor care for persons with dementia, as well as to sustain the effective functioning of health and social care systems. To date, the high volume of research related to care at home and acknowledged low impact of interventions suggests that a re-examination of the nature of care at home, and how we come to know about it, is necessary if we are to advance strategies that will contribute to better outcomes for families. This paper describes findings from an ethnographic study that was designed to support an analysis of the complexity and materiality of family care arrangements - that is, the significance of the actual physical, technological and institutional elements shaping care-giving situations. In this paper, we describe the arrangements made by one family to show the necessary collectivity of these arrangements, and the consequences of the formal care system's failure to respond to these.
\end{abstract}

$\boldsymbol{K E Y}$ WORDS - Alzheimer's disease, family care-giving, dementia, ethnography.

\section{Introduction}

Providing responsive care services for older people, particularly those with Alzheimer's disease and other dementias, is arguably the biggest challenge in health care policy and practice today. Alzheimer's disease and other

* Faculty of Nursing, University of Alberta, Edmonton, Canada.

$\dagger$ School of Nursing, Faculty of Human \& Social Development, University of Victoria, Canada. 
dementias are among the most feared problems of ageing (Canadian Institutes of Health Research 2013), as well as being a significant cause of disability in those over the age of $6_{5}$ (Alzheimer Society of Canada 2016; Alzheimer's Disease International 2016). It is estimated that 45 million people are living with dementia worldwide, a number that is anticipated to increase as the population ages over the next 25 years (Alzheimer's Disease International 2016). While some of the apocalyptic predictions of a 'grey tsunami' can be questioned, there is certainly evidence of increased longevity and related chronic illness (Wu et al. 2016), with dementia being one health condition of ageing that presents as a major challenge in both community and public care settings.

Similarly to most developed nations, in Canada, the setting of this study, more than half of those with dementia are living at home with family and community support. By 2038, this number is expected to rise to 62 per cent of people with dementia living at home with moderate to severe cognitive impairments (Alzheimer Society of Canada 2010). With more people living at home, the need for home-based care will increase and it is primarily family carers who will provide this crucial support to family members. It is clear then, that family carers make, and will continue to make, a substantial contribution to the sustainability of health and social care systems. Appropriate support for family carers is thus essential to minimise risks to their health, to prevent premature institutionalisation or poor care for persons with dementia, as well as to sustain the effective functioning of health and social care systems (Canadian Institute for Health Information 2010).

However, decades of research into the experience of providing homebased care to a family member with dementia has recently been assessed as having had little effect in relieving or reducing the 'burden' of that care (Purkis and Ceci 2015; Zarit and Femia 2008). Though some part of the difficulty of providing support to families is related to specific political and economic contexts, an analysis of the care burden intervention research suggests that key assumptions of the research may limit knowledge development and intervention effectiveness (Purkis and Ceci 2015). Especially problematic are, first, an overriding focus on the isolated caregiver-care recipient dyad as the appropriate object of inquiry and target of interventions, and, second, limited analysis of the materiality or complexity of families' actual care practices; that is, a failure to appreciate the significance of the physical, technological and institutional elements shaping care-giving situations, and importantly, how the interplay among these works to make up a family's care context. This means that the complexity of care situations - the diversity of people, objects, places and issues involved - often appear in research primarily as methodological problems, 
variables to be controlled through more a rigorous application of method. The high volume of research and acknowledged low impact of interventions, however, suggests that a re-examination of the nature of care at home, and how we come to know about it, is necessary if we are to advance strategies that will contribute to better outcomes for families.

\section{Learning about family care practices: about the study}

This research was designed to counter the overriding focus on the isolated care-giver-care recipient dyad in much research concerned with family care-giving practices, and specifically to enable the development of an analysis that can account for the complexity of family arrangements. To achieve this goal, the methods of ethnographic case study were used to trace the arrangements people make to sustain and improve everyday life when one member of the family has dementia. In this context, the specificities of diagnostic categories, i.e. type or stage of dementia, were not foregrounded but rather we were most concerned with how families handle a growing mismatch between the person with dementia, the daily environment and fellow beings (Moser 2011). As Gaines and Whitehouse (2006) observe, a critical issue in dementia is the ability to carry out activities of daily life - dementia matters in terms of the ability to hold everyday life together and that ability is relative to context, resources and requirements, i.e. what people are expected to do and what conditions are in place to help them. Two questions guided all elements of the study:

1. How do people with dementia, their primary carers and extended family members make arrangements, mobilise resources and access formal assistance to make everyday life as good as it can be?

2. How do local systems of health and social care effect everyday life and care practices for people living at home with dementia and their families?

The study was conducted using traditional ethnographic methods of observation, interview and document analysis (Hammersley and Atkinson 1995), beginning with interviews with individuals knowledgeable about the local formal care context in two urban centres in a Western Canadian province and an analysis of policy and programme documents describing this context. The principal investigator (Ceci) then undertook fieldwork with families, comprised of observation and interviews. Three participant families were recruited following presentations about the research at 'caregiver support groups', with family members contacting the researcher following these presentations to express their interest. A fourth family 
contacted the researcher after learning about the study from a case manager. In each case, a follow-up meeting to discuss the study, answer questions and obtain formal consent was arranged and followed by an initial interview in which families shared the history of their situation. Because families' willingness to participate in the research included their agreement to have the principal investigator 'go along' with them as they engaged in their usual everyday activities, seeking consent for the researcher's presence was also an ongoing and continually negotiated process. For participant families, participation involved unobtrusive observation and interactions in the course of their everyday, ordinary activities, and thus they were not deemed to be exposed to risks that were in and of themselves greater than the risks of ordinary life. However, researcher access to 'private' areas of family life, and the relationship that develops between the researcher and participants through prolonged engagement, were understood to constitute potential risks for families. The key strategy to mitigate this risk was to conduct the research as overtly as possible, making the researcher role clear at the outset and on an ongoing basis, as well as seeking ongoing permission to be present during field visits. Four families were followed for periods of four to 12 months, beginning in March 2015 and ending in January 2017. In all the cases observation ended soon after the family member with dementia was institutionalised. Ethics approval was received from the University of Alberta Health Ethics Research Board.

The intent of the fieldwork was to start from a specific situation and then to map who and what was involved, and what was being done, in order to learn about the relationships through which care was accomplished. Periods of observation lasting one to two hours encompassed everyday activities and routines, including visits at home from health-care providers, as well as going along with families to doctor's appointments, day programme visits, and other recreational and social activities. During these activities, brief notes were taken of events and conversations that were then developed into more comprehensive and descriptive fieldnotes. Fieldnotes also included notes of telephone conversations and email updates from families. Additionally, the initial family interviews and key informant interviews were transcribed verbatim.

As is usual in research of this type, analysis of data was ongoing and iterative, involving close reading and re-reading of fieldnotes, transcripts and other documents to develop understanding in relation to the study questions of what makes care for a family member with dementia possible or impossible, easier or more difficult. Sensitising questions included who are the people and things involved here? How do they attend to one another? What are the things that matter? How do they matter? This textual process of analysis occurred at several sites. In July 2016, for example, one complete set of 
anonymised fieldnotes and transcripts (Family 3) was the focus of discussion at a theory workshop attended by all the research collaborators. ${ }^{1}$ In this setting, key events and concepts were tested as potential frames for analysis, including discussion of the above-noted questions and the study's overall framework of material semiotics as a tool to study care practices. On completion of the fieldwork (January 2017), fieldnotes and transcripts were analysed as a whole by the three Canadian members (Ceci, Symonds Brown, Purkis) of the research team. Working individually, and using the same textual processes of reading and re-reading, fieldnotes were annotated with observations and insights that drew out the associations or relations evident in the data. In team discussions of this work, no attempt was made to identify themes in the data but rather focused on topics of specific analytic concern. Analysis was thus informed by pre-developed sensitising concepts and questions but researchers worked to maintain an open empirical perspective-that is, remaining responsive to the interplay of empirical and theoretical elements, and describing events in observational language (Mol, Moser and Pols 2010). The compilation of individual observations resulted in layered descriptions of the highly specific care practices that families have worked out in order to be able to live their lives.

This paper draws on data from one family to show the constellation of people and things that make up a family's arrangements for care. Although we make no claim for the generalisability of this family's arrangements and experiences, we do suggest that the data presented serve as an instructive case. In this we are aligned with Law's (2008) proposal that in working through examples or cases, we learn in concrete rather than abstract terms and, in so doing, create space to engage the questions with which we are concerned. To show this family's arrangements we describe the initial meeting with Colleen, a family outing and a visit to the doctor's office, and then show how Colleen's careful arrangements are undone when James is expelled from the day programme. Through these data we learn about how people are positioned in relation to one another, how particular actions are accounted for and how various materials or things are incorporated into what comes to be recognisable as a 'care-collective' (Winance 2010). Importantly, we can also begin to see how the lack of recognition on the part of formal care systems of the necessary collectivity of care arrangements precipitates, rather than delays, James' institutionalisation.

\section{Colleen and James Miller: managing 'dementia'}

Colleen and James Miller (all names are pseudonyms) have been married for over 40 years, she is 61 and James is 66. Colleen and James have one 
son, who is married with two children, and lives nearby. James has several siblings who also live in the same city, as do his parents. James and Colleen live in a large, comfortably furnished home in a quiet neighbourhood. Colleen says they have no financial concerns, as she has been astute in managing their money. They had a fairly wide circle of friends but many of these have dropped away as James' behaviour changed and he was no longer able to participate in their usual activities. About three years ago, Colleen started noticing changes in James - at first she thought he was 'being arrogant' or ignoring her because he was not responsive then she thought it might be his hearing but the hearing tests were normal. She noticed he was repetitive and that it was difficult to engage him in activities. Multiple medical appointments resulted in a diagnosis of 'Alzheimer's disease' about one year ago.

When asked what has been most difficult over the past few years, Colleen says it is simply getting James to do the things he has to do, e.g. getting him to doctor's appointments requires her to hide the appointment in some more desired activity, like visiting his brother. James tends to simply refuse to do things and getting around that can be difficult. At this point, James goes to a day programme three days a week, which is unusual as patients are usually only allowed a maximum of two days. Colleen got around the limit by arranging to have him attend two different day programmes, and the extra day is subject to space at the programme. One of the troubles she has with James is that he will listen to anybody but her - she says it is because they are together too much, and because he has retained his 'basic social skills' - he is polite to other people but with her he is rude and angry. This turns out to be the biggest concern for Colleen; she sometimes feels unsafe with him. Over the past few months, she describes him as having become more restless, pacing, easily agitated and harder to redirect. The first visit with the Millers was with Colleen alone; James was at his day programme.

Colleen is 61 , appears fit and healthy though a little tired. We have coffee in the kitchen, the house is comfortable and very tidy. Close to the beginning of my visit she shows me two 4-inch binders of all of the information she has collected over the past couple of years - it is from many sources and contains information about local resources available, as well as financial and legal concerns; she also shows me a notebook she keeps with a record of all her contacts with the formal health system i.e. case managers. The notebook also includes notes about James, his behaviour and things that happen. A reason she gives for this collection is that she is always asking herself, am I missing something? She has taken multiple courses including a correspondence course on 'dealing with dementia' from the University of Tanzania - she says she is 'always looking for a course that can help'. (Fieldnotes, March 2015)

Drawn into this family's arrangements are things that help to create a sense of control - a tidy living space, binders full of information that will help 
Colleen deal with the present and plan for the future. The notebook suggests that keeping track of details is important, and also that it is difficult to keep track - the problem is not knowing what might be important. It seems that the things she needs to keep track of are things she values as giving her control - she is working hard to have things go as smoothly as possible under the circumstances. So contributing to care and to the family's arrangements are the notebooks, binders, courses that enable her to make something that runs smoothly. The relations Colleen makes are with these 'things' that offer some stability - the documents in the binder are the documents in the binder, the notebook that records her contacts affirm these contacts. The notebooks in particular work to establish the 'reality' of her situation, tracking the 'private' experiences she has that most other people never see.

Colleen is a good manager; she is organised, prepared, she has done her homework - part of her work is to 'get around' barriers, whether they be James' intractability or the eligibility rules of various community resources. We can see then, that for Colleen, dementia is an unpredictable kind of thing that must be managed and the work of managing this condition, and knowing about it and what can be done in relation to it, is distributed across the binders, notebooks, courses, other books she reads, people she talks with - the doctor, the case manager, the people in her care-giver support group. What needs to be done is to know about this; manage it.

\section{Family arrangements: the hockey game}

Given one of the goals of the study was to develop some understanding of the arrangements families make, Colleen suggested that going along with the family to their grandson's hockey game would show something about what their everyday life was like.

The arena was cool but not cold, rows of backless bleachers lined each long side of the rink -5 rows with a walkway behind. The seats were filled with mostly young to middle aged adults (about 30 people).

Colleen spotted me right away and waved me over to the family group. She had brought a cushion for me to sit on and seated me next to James. James was sitting on a kind of stadium chair - a cushion with a backrest. Also present were James's brother, seated on his other side. Next to me, between Colleen and myself was her sister-in-law. A few minutes into the game, Colleen's daughter-in-law and granddaughter (aged about 12) joined the group. They sat in front and to the side of where I was seated beside James. Neither greeted James on their arrival but did so several minutes later.

As soon as I sat down and was introduced to James, he fired off a series of rapid stream questions: did I know how long he worked for the city? how tall was he? how tall was 
his son? what did he weigh? where was he born? how many dvds did he have in his house?

I observed little verbal interaction with James, his verbal responses seem limited to the questions he asks, though he does respond to typical social cues i.e. shook my hand when I was introduced to him, nods and smiles when spoken to.

The game was over at 12:45 and James immediately stood and started walking down the passageway. Colleen called to her brother-in-law to go with him (apparently, he was looking for a bathroom). The family quickly gathered their things and left, following James and his brother down the passage. (Fieldnotes, March 2015)

A first thing to notice is how James interacts - his main conversation is the questions he asks, and they are questions about himself, that he would know the answers to, that his family may know the answers to, but not ones an outsider would know. This could be how he now makes relations with others. The next thing is the care taken of him-he has a special seat, one with a back that keeps him comfortable and thus encourages him to stay in his place. The seat works with him to accomplish him staying seated as it also cues him that he has a 'spot'. His brother sits beside him and the researcher is seated on his other side. But nobody really talks with him, but then, he does not offer much conversation except his questions. But he watches the game, and claps. Looking at James, there is nothing to make you think this man has dementia - there is no special notice taken; here he is one of a family group-though Colleen does keep an eye on him. Colleen brought a cushion for the researcher as well, and placed it next to James so it was clear where she was to sit. It seems she had everything all arranged with James' brother on one side of him, the researcher a safe bet to place on his other side because neither would be surprised by anything James might say or do.

His family is all around him, though it is also the case that they do not talk much with him, though they talk easily with one another. The situation suggests a family outing is valued - family members are brought in contact with each other, sharing the experience of watching the grandson play hockey. Does Colleen also want other members of the family to see James? To 'enroll' them into his care - or at least engage them in her concerns and experience of what it is to care for him now? So through this perhaps she can draw on them for support when things become too much for her?

The outing itself is a normal kind of thing, there are many other families here. Bringing James does not seem to have presented any problem, and no problems arise - except maybe at the end of the game when James gets up and heads down a corridor - but Colleen anticipates, knows that he is looking for a bathroom and draws in James' brother to follow him. So while James' dementia is often a problem for Colleen, here it is not, in part because she draws other family members into both the work of 
monitoring James, and sustaining a relation with him - of being with him and her in a public place. In the arena, James is simply a grandfather and hockey fan - a familiar biographical narrative that might not be sustained if his family did not work together to make his presence as calm and engaged as possible. Doing this together seems important to Colleen, perhaps she worries she would not be able to manage it alone - she requires these reinforcements to enable it to happen, it brings about a connection with these other people, one of whom (the brother) cares for James by following him to the bathroom.

\section{The clinical regime: a visit to the doctor}

I arrived early to the [clinic site] site, it's a grey, foggy cool morning - and observed Colleen and James arrive. Colleen is driving. She leaves James in the vehicle and goes into the building - she returns approximately 5 minutes later with a parking pass, and he gets out of the car and walks into the hospital with her. I meet them inside. The appointment is for 9. Colleen gets James to sit in a chair and gives him an iPad with a word search game open - she says that he will sit for hours doing these, that he was 'going through a book a day' before she found the game on an iPad, now there are endless variations.

A woman brings Colleen and I into the doctor's office, Colleen asks if it is okay if I sit in on the appointment. I introduce myself and give the doctor information about the study. She and a student doctor sit at a round table - Colleen sits with them and I sit off to one side. Colleen brings out her notebook and begins recounting a number of incidents since the last appointment. The concern for the doctor and Colleen is that James is 'becoming a little more challenging' - he can be 'explosive', which has now been witnessed by other family members. The doctor says that placement is the 'looming issue'. Colleen continues to describe experiences since the last visit - when she had set up an evening to play cards with friends, James had put away things that should have been left out (serving platters etc.) - this was very frustrating for her. But he 'did well' playing cards that evening - until about 10:30, then he lost track of whose turn it was and 'lost it'. She describes needing to be aware of how long he tolerates being away from home, being with people. Colleen tries to problem solve his 'breaking point' - is it time? is it location?

The doctor listens, and then responds that it is probably a 'combination - being out of his element, fatigue, and the activity may have been 'challenging' - these things together may lead to 'catastrophic reactions' when he is overwhelmed and cannot meet expectations. Outings may need to be shortened, or maybe 'no outings' - in which case - 'someone will have to stay with him' when Colleen goes out. They will have to 'accommodate' his changing needs/behaviour to continue to allow Colleen to get out.

They discuss effects of Risperidone which James is now taking - with the doctor suggesting that it may have effects on his cognition - 'can tamp down his temper but he is more mixed up'. She asks 'has it (the Risperidone) helped?' Colleen 
responds 'I think it has' but it is hard to tell because of multiple factors - time, home, routine.

Focus is on managing behaviour through routines. Colleen says 'he is losing some of his words'. Doctor responds 'you are doing an incredible job' - tells the other doctor present that she has done so much to educate herself. Colleen says 'ignorance is not bliss' - gives her a capacity to deal with things. The doctor observes that James is 'not the James you married'.

At this point, James is brought into the room and is seated at the table, Colleen moves her chair away from the table and out of James' line of vision. He asks his rapid fire questions [see previous fieldnote] - the doctor laughs and says she does not know these things. She asks him other questions that are related to the questions he asked i.e. he asks, where was I born? she asks, what day of the week were you born on? The doctor asks him about current events, he ignores these questions and repeats 'facts' he has already said. Her questioning of him is persistent, pushing him to respond to her questions - he does not. (Fieldnotes, March 2015)

There is a lot going on in this meeting with the doctor. James is not present in the first part - he has been left on a chair in another room, playing games on the iPad. The iPad is something that 'cares' for James - it engages him, keeps him in one place, keeps him calm. He can apparently do word search games on the iPad for hours. It almost sounds as though the rate of his use of books, before the iPad, was out of control; the 'endless variations' contained in the iPad helps to keep this activity contained as well. It helps Colleen by keeping him occupied, allows her to leave him alone, and get on with doing other things without worrying about what he is up to. The work of monitoring James is sometimes delegated to the iPad.

The purpose of the meeting with the doctor is not stated but it seems to be organised as an update on 'progress'. Without being asked, Colleen shares information from her notebook, these are incidents that describe her trouble managing James - she describes the behaviour as explosive. This is something she has worried about for a while, but now other family members have seen these events as well, which Colleen thinks will help them to see that James cannot live at home with her much longer. This difficult decision may be another reason she works hard to keep other family members involved in his care - so that they can witness what he is like. Perhaps this is more important in this case because of his ability, as demonstrated through his iPad use, to be focused. That ability is so strong they might not otherwise see his outbursts. The notebooks act as form of witness to what is largely invisible work, as does bringing extended family members into the arrangements.

The focus of much conversation is an evening Colleen had arranged to play cards with friends - this was something she and James used to do regularly. First of all, her preparations for the evening were hampered by James, putting things away just as she had set them out. And then during the card 
game itself, several hours into it, he 'lost it' when he seemed to have lost track of the game itself. In some respects, this seems quite remarkable that he would have this much ability to participate in a group activity and yet they are talking about the 'looming issue' of placement. The card game, the evening with friends, as well as being a social event, seems to serve as a test of James' 'breaking point', an activity mirrored in the clinic appointment when the doctor pushes James with her questioning-and again a few weeks later during a visit from an occupational therapist who aggressively questions James while following him around the house (fieldnotes, April 2015). This idea of James' breaking point seems to act as a co-ordinating mechanism, so while part of Colleen's work is bringing normal social relations into their home through arranging an evening of cards with friends, she also seems to have learned to mirror the 'tests' of clinic visits and brings these in as well. In this she is produced as an extension of the clinic, collecting data, setting tests, evaluating James and thus enacting 'model care-giver' as she provides 'clinical examples' of James' dementia. 'Dementia' as enacted through these home activities is being made and measured, in part, through a re-creation of the local practices of testing characteristic of clinic visits and the transfer of these practices into their home works to configure Colleen and James, their home and their relations, in clinical ways.

In discussing the evening of cards with the physician, Colleen seems to be trying to sort out what happened. She speculates that maybe the evening was too long, and that one of the things she needs to pay attention to is how long James can be engaged with others. She is trying to problem solve, and the problem is predicting James' 'breaking point'. This seems important to her as being able to organise their lives in light of his tolerance for various kinds of activities would be helpful, and it seems possible that she imagines there is an underlying rationality to his behaviour that the medical team might help her to excavate. The doctor listens, but the reasons for James' behaviour do not seem to be something she knows about either. She offers possibilities - fatigue, James feeling challenged or overwhelmed with what he is being asked to do-they attribute this to him as though he is fully cognisant of his limits. But at the same time, the doctor seems to be saying something about avoiding a mismatch here, as that mismatch can lead to trouble - or in her words, 'catastrophic reactions' - language which seems larger than both the problem she is describing and her advice - shorter outings or no outings. If the latter, then someone will have to stay with James at home so Colleen can continue to go out. However, it is not stated why this is necessarily the case. Even if James is seen to become overwhelmed by expectations encountered in social events, it is at least possible that he might still be quite capable of 
being able to occupy himself at home in familiar surroundings. It is not clear why inability in one sphere spreads to all spheres so quickly and completely.

But as well as changing arrangements to accommodate James' volatility, there are also pharmaceutical interventions to manage such behaviour; and James has been on this type of medication for some time - it is a trade-off though, in order to 'tamp down' James' temper, his thinking is made more muddled, which may make him feel overwhelmed and angry. When asked if the Risperidone has helped, this is hard for Colleen to say-she says instead that there are too many other issues at play-the time of day, what activities they are doing and where they are. She is right - there are so many variables, and everything is in play all the time.

So a problem here is James' behaviour despite efforts to contain him his temper, his potential to be 'explosive', the possibility of 'catastrophic reactions' - which must mean, though no one actually says this, the potential for James to become violent and harm Colleen or others; and it is true, he is an imposing man - he could do some damage. How to control this possibility? There are changes to be made in routines, staying alert to what overwhelms him, looking out for the possibility he will become frustrated, making sure he does not become too tired, or be away from home for too long. But these interventions are somewhat uncertaindependent on Colleen's abilities to read James and the situations they are in-misreading has some serious consequences. So there is also medication that tamps down his temper, even though he may become more confused. But what trumps everything in this situation is safety, keeping James on an even keel - the work of doing this is distributed between Colleen, the medication, the routine of three days a week spent at the day programme away from Colleen and, sometimes, the iPad. These activities may work to delay institutionalisation, but that this may not be enough is suggested by the doctor's comment that placement is a 'looming issue'.

Perhaps we can see here why Colleen has done so much work to 'educate' herself - her partner can be, at times, difficult to predict, a threat to her safety. Her work here is praised by the doctor - she is a model care-giver, educating herself, working to prevent problems, being proactive, keeping James at home as long as possible. There are ways that we can see that James has been constituted as an 'object of dementia work' for Colleen, no longer the man she married. Also she, from a medical stance, is showing a good response to James' signs of dementia: a record is kept of him, and his activities are reported on and discussed in terms of signs and symptoms, possible interventions. This is a clinical rather than spousal or domestic repertoire, partly oriented to processes of neuropathology, but also to issues of dependency, the politics of family life and even to larger 
socio-economic issues related to family responsibilities and health system sustainability. As Cohen (1998) observes, what dementia 'is' in our times is all of these things - it may be a term that presupposes a pathology of the individual but at the same time its meaning enacts debates about the organisation of family life and a society's economic resources. To tell about dementia through a framework that is largely neuropathological overlooks the local and contingent practices of enacting dementia that tell about what is at stake - in this situation, it is not possible to choose which are the most significant contributing factors: James' particular neuropathology, the history of their family life, the social resources available to help manage him.

\section{The 'crisis': 'it only takes one thing'}

The last excerpt from the fieldnotes describes a telephone conversation with Colleen:

I missed a call from Colleen, she left a text 'please call when you have time for an update' - I called later the same afternoon. She wanted to tell me what had been happening over the past week or so. Her story: about ten days ago, the coordinator of James' day program had called to report that James had started screaming at another patient while waiting for the Access bus to come home. This is another man who 'agitates' James - they are usually kept apart but somehow that had not happened on this day. Questions were raised as to whether James would be able to continue going to the day program. The coordinator called again that Friday, and said that Colleen should have James 'checked out' by the family doctor. A plan was made for Colleen to accompany James to the day program as an 'observer'.

But before this could be arranged, there was another incident over lunch at the program where James became agitated. Colleen tells me that the staff of the day program talked and they made the decision to discharge James from the day program, and then called Colleen to inform her of this. Colleen called her case manager, her family doctor and the geriatrician. She could not reach her case manager. Says the situation was difficult for her because it was 'a decision she did not make', i.e. they just called and informed her what they were going to do.

She says 'a crisis hit' and she expected 'people to respond' - she called the case manager's manager who said she would set up a strategy meeting. Home care have offered companion care [a home support worker who would come to the home] - but Colleen has conditions - it must be the same person every time, they must come in the morning, be male, be aware of James' triggers. She says that transition services also got in touch with her and asked about 'decanting' him - he would be a priority 1 placement, for the first available bed with option to transition him to a choice location when possible.

They have 'left it in my hands' and if it gets to be too much, she can make the decision. 'Do I let companion care in or not?' She says she has her support group tomorrow and will talk it over with them. I asked what would happen with James while she's 
at her group - she will 'sit him in front of the TV and leave him'. Her son's wife will telephone him and check to make sure he is okay.

I asked how she was doing with all these changes this week. She says she was 'very upset' that they discharged him, and that she had 'choices taken away from me', and she then realized she was 'treating this like a job, this is my job and I am not in control of it'. Now she is focused on rearranging things to make things work again. When this happened, she wondered, 'who do I call? Which one of my resources do I call? The family doctor called me right back but could not do anything, the geriatrician does not work on Fridays, the case manager did not call back - I'm running around, hearing people do not work that day, not getting responses - feeling frustrated, angry, emotional-things happen fast and it only takes one thing'. (Fieldnotes, April 2015)

James' participation in a day programme three days a week does several things. It gives Colleen and James time away from each other, it gives Colleen time to do the things that make up her 'normal' life, it gives James a routine that is his own. Having this activity taken away from them creates a 'crisis' - even though on the surface nothing in particular seems to happen, except that he does not go to the programme. But that the situation is so critical suggests that it matters a great deal - the work of caring for James must be redistributed. What seems to need to be maintained is time for Colleen and James to be apart. James' discharge from the day programme is also important because it ends up precipitating his admission to long-term care, it makes him a priority for placement - and we can see that the work done by the account of him as someone who is volatile, quick to escalate into screaming and even lashing out physically, contributes significantly to this prioritisation. Yet at the same time, when he asks Colleen about going to his programme, and she tells him the programme has ended, he is calm, which seems contrary to this construction.

It is notable that the staff at the programme knew James and the other person did not mix well but they suffer no consequences when James and the other man, finding themselves together, begin yelling at one another. Had this not happened, one wonders how much longer he might have been able to attend. But in any case, it is James who will bear the brunt of inadequate organisation on the part of the programme who respond by redistributing the work of managing him to the family doctor, who should 'check him', and to Colleen. It also appears that a show of aggression in the 'formal' system is treated differently than what happens in the privacy of the home, suggesting what behaviours are visible to who really matters. This is a paradox of a system that distributes care to home and family but then, following formal observations of issues, acts unilaterally to alter that distribution leaving Colleen as sole care provider until new arrangements can be made. It seems clear that, in acting unilaterally, the day programme 
does not see itself as figuring into a collective arrangment, part of a network of care that is working to delay James' insitutionalisation. In fact, what we see is the day programme, understood perhaps as one 'room' in a thing called 'care in the community', treating Colleen and James' home as simply an extension of that care system, and a part that need not be considered all that significant.

So what is involved? There is the co-ordinator of the day programme and other staff who make the decision to discharge James, there is another patient who he 'screamed' at, there is a family doctor who is supposed to 'check out' James, though it is not at all clear what he would check. There is Colleen's case manager who does not return her calls, a geriatrician who does not work Fridays, and then the case manager's manager who will set up a strategy meeting. For Colleen, there are all these people who are not responding properly to her situation, who have made decisions, who have decreased her options. She has invested so much time and effort into being prepared ... now all these people are letting her down, just when she most needs them.

What is also evident in the data are the different normativities involved. For the day programme staff, this must be keeping other patients safe, not having an unpredictable patient there; and yet, for all this being important, they evidently cannot ensure these two individuals are kept apart during the day. For the case manager's manager, she attempts to patch up the system, stepping in for the missing case manager and receiving in return Colleen's anger. For Colleen, she has been doing her part, she has been careful making arrangements, but her carefulness is easily undone and the precarious control she has worked hard at achieving turns out to be pretty ephemeral. But the precariousness experienced is not so much in Colleen's arrangements but in the formal system's vague, subdued (non)-response to the family's situation. And through this all, a ground has been prepared for James to be determined as someone who is 'erratic' and potentially 'explosive' and so, even though there is a last-minute glitch in the unfolding of events, there is an inevitability here in his final disposition.

Colleen has had a plan, a plan that included other family members' awareness of James' condition, regular contacts with formal care systems, medication and technologies to manage behaviour, and the day programme, time for them to be apart. Colleen's plan also included eventually arranging a move for James to long-term care. The day programme discharge disassembles her careful arrangements and she is, in a sense, defeated when the precariousness of her arrangements, and the futility of her plans, becomes quite visible. It is a problem that the structures she relies on, the arrangements she makes, are so brittle, breakable - depending on relations with other people who are not, perhaps, working in the 
same way she is; they are not 'in time' with her and we can see that it may be this gap that creates burden rather than the actual care.

\section{'Care' in the community?}

The focus of this research is families who are trying to care in contexts where there is no easy accommodation for the 'abnormality' of their situations. In the face of the work that has been allocated to them, families work out highly specific ways to live their lives - a practice of tiny multiple adjustments, localness and multiple paths. This just is how people arrange things. If delaying institutionalisation for persons with dementia is indeed a social goal, the crucial point may simply be that supporting families actually requires good understanding of how their arrangements work and what supports them, and how formal care services figure into all of this. The events described above, however, call into question the everyday claim that health and social care systems are working hard to avoid and/or alleviate the 'burden', both system-wide and family-centred, understood to come along with an ageing population, and it is worth noting that the experiences of this family in their interactions with the formal care system are not uncommon (Egdell et al. 2010; Exley and Allen 2007; Pickard and Glendinning 2002; Ploeg et al. 2017). There is a mismatch between the overriding message that there is 'no room' in the formal system, that care must happen at home as much as possible, and a system that does not seem able to function to keep someone who appears as high functioning as James at home.

Significantly, through this case we can see the ongoing constitution and reconstitution of a 'care-collective' (Winance 2010), a gathering of people and things that includes James and Colleen but also doctors, extended families members, case managers, iPads and television shows, binders of information and notebooks, clinical practices and biomedical discourses, day programme protocols and everyday routines as well as, and importantly, the relations made among all of these. This 'care-collective' is made up of what is brought into the arrangements and what is kept out (Callon and Law 1997; Callon and Rabeharisoa 2004; Winance 2010), and even this partial accounting of a family's arrangements shows that what contributes to care is multiple and diverse. It also shows that care in a family when one member has dementia requires a collective, and that it matters what kind of collective. For Colleen and James, in a context where perhaps the most difficult thing is managing behaviour that is, or may be, aggressive, day programme protocols matter. These matter, for instance, when they intervene to derail a family's arrangements, when the apparently inflexible practices of the day programme cause James to be 
discharged for showing the behaviour for which he has been enrolled in the first place. This practice interferes in Colleen's arrangements and produces her as a 'care-giver in crisis'. Her trouble here, however, is not so much James' 'dementia' but the inflexibility exhibited in that part of the care-collective or perhaps more pointedly, that the day programme sees itself as external to, rather than part of, the collective that 'cares' for James.

Two other observations can be made here. First, and perhaps somewhat controversially, despite the claim that people such as James are being cared for in 'the community' and that this community is somehow different, and better, than an institution, there is a strong sense in which the world of Colleen and James has come to resemble one big institution. As noted previously, if we take the day programme to be a 'room' that contains James for part of the time, his discharge treats the Miller's home as merely an extension of the larger care system; he is 'transferred' by fiat from the expert system to another 'room' where he will be held until new arrangements can be made. Colleen's highly developed clinical repertoire both reflects and enacts the porous boundary between institution and home as she performs a trajectory of regular monitoring to measure change. Secondly, Colleen's experience of the unavailable 'case' manager, missing just when she needed her, underlines the 'myth' of individualised care that is assumed to characterise care in the community. Colleen seems to think she and James are an individual case, to be responded to in an individualised way. The reality seems to be that the case manager, for all sorts of reasons including large caseloads, seems only able to look out for them as an 'instance' of a much larger problem she has to deal with. Nothing is ever at the 'right' time and the promise of individualised care fails to materialise. Instead, the formal care system's responses to Colleen and James' troubles are blunt, with little nuance - a more supportive system would need to be other than this, less 'all or nothing' and with more things 'in-between'. This returns us to the idea of 'care-collectives'. While it may be the case that James 'has' dementia, the specificities of the care setting, the practices of the people and things involved, and the relations made between, are also participating in this particular enactment of his disease ( $\mathrm{Mol} \mathrm{2002).} \mathrm{In} \mathrm{this}$ case, it is not at all clear that James 'needs' to be institutionalised, but it does seem clear the relations enacted among a broad range of actors have made this practically inevitable.

\section{Strengths and limitations}

As noted previously, no claim is made for the generalisability of this family's experience, which is sometimes understood as a limitation of the 
methodology employed here. However, given the research questions, the approach supports the necessary attention to detail, context and complexity that would be difficult to attain otherwise. The possibility of limited perspective related to a single investigator collecting data, as well as in an extended relationship with the participants, was mitigated by the team approach to analysis.

\section{Acknowledgements}

Special thanks to all the families who participated in this research. The research was funded by a Canadian Institutes of Health Research Operating Grant (CIHR MOP 133462). The funding agency had no role in design, execution, analysis or writing of the study. The study received ethical approval from the University of Alberta Ethics Review Board (ID Prooo045783). All authors contributed to data analysis and conceptualisation of the paper. The first and second authors had primary responsibility for writing. There are no conflicts of interest.

\section{NOTE}

1 The 'Delaying Institutionalising, Sustaining Families' research grant was initially conceived as a multi-site international collaboration. Funding difficulties in some sites meant that the collaborative elements of the study consisted mainly of contributions to theoretical framing and analytical standpoint. Co-investigators included in theory meetings were Ingunn Moser (Norway), Jeannette Pols (The Netherlands) and Kristin Bjornsdottir (Iceland).

\section{References}

Alzheimer Society of Canada 2010. Rising Tide: The Impact of Dementia on Canadian Society. Alzheimer Society of Canada, Toronto.

Alzheimer Society of Canada 2016. Prevalence and Monetary Costs of Dementia in Canada. Alzheimer Society of Canada, Toronto.

Alzheimer's Disease International 2016. World Alzheimer Report-Improving Health Care for People with Dementia. Coverage, Quality and Costs, Now and in the Future. Alzheimer's Disease International, London.

Callon, M. and Law, J. 1997. After the individual in society: lessons on collectivity from science, technology and society. Canadian Journal of Sociology, 22, 2, 165-82.

Callon, M. and Rabeharisoa, V. 2004. Articulating bodies: the case of muscular dystrophies. Body and Society, 22, 10, 183-203.

Canadian Institute for Health Information 2010. Supporting Informal Caregivers - The Heart of Home Care. Canadian Institute for Health Information, Ottawa.

Canadian Institutes of Health Research 2013. Living Longer, Living Better. CIHR, Institute of Aging, 2OI3-I8 Strategic Plan. Canadian Institutes of Health Research, Ottawa.

Cohen, L. 1998. No Aging in India: Alzheimer's, the Bad Family and Other Modern Things. University of California Press, Berkeley, California. 


\section{Christine Ceci et al.}

Egdell, V., Bond, J., Brittain, K. and Jarvis, H. 2010. Disparate routes through support: negotiating the sites, stages and support of informal dementia care. Health Eं Place, 16, 1, 101-7.

Exley, C. and Allen, D. 2007. A critical examination of home care: end of life care as an illustrative case. Social Science $\mathcal{E}$ Medicine, 65, 1 1, 2317-27.

Gaines, A. D. and Whitehouse, P.J. 20o6. Building a mystery: Alzheimer's disease, mild cognitive impairment, and beyond. Philosophy, Psychiatry, and Psychology, 13, 1, 61-74.

Hammersley, M. and Atkinson, P. 1995. Ethnography: Principles in Practice. Second edition, Routledge, London.

Law, J. 2008. On sociology and STS. Sociological Review, 56, 4, 623-49.

Mol, A. 2002. The Body Multiple: Ontology in Medical Practice. Duke University Press, London.

Mol, A., Moser, I. and Pols, J. 2010. Care: putting practice into theory. In Mol, A., Moser, I. and Pols, J. (eds), Care in Practice: On Tinkering in Clinics, Homes and Farms. Transcript, Bielefeld, Germany, 7-25.

Moser, I. 2011. Dementia and the limits to life: anthropological sensibilities, STS interferences, and possibilities for action in care. Science, Technology and Human Values, 36, 704-22.

Pickard, S. and Glendinning, C. 2002. Comparing and contrasting the role of family carers and nurses in the domestic health care of frail older people. Health and Social Care in the Community, 10, 3, 144-50.

Ploeg, J., Matthew-Maich, N., Fraser, K., Dufour, S., McAiney, C., Kaasalainen, S., Markle-Reid, M., Upshur, R., Cleghorn, L. and Emili, A. 201 7. Managing multiple chronic conditions in the community: a Canadian qualitative study of the experiences of older adults, family caregivers and healthcare providers. BMC Geriatrics, 17,4 .

Purkis, M. E. and Ceci, C. 2015 . Problematising care burden research. Ageing $\mathcal{E}^{2}$ Society, 35, 7, 1410-28.

Winance, M. 2010. Care and disability. Practices of experimenting, tinkering with and arranging people and technical aids. In Mol, A., Moser, I. and Pols, J. (eds), Care in Practice: On Tinkering in Clinics, Homes and Farms. Transcript, Bielefeld, Germany, 93-118.

Wu, Y., Fratiglioni, L., Matthews, F. E., Lobo, A., Breteler, M. B., Skoog, I. and Brayne, C. 2016. Dementia in western Europe: epidemiological evidence and implications for policy making. Lancet Neurology, 15, 1, $116-24$.

Zarit, S. and Femia, E. 2008. A future for family care and dementia intervention research? Challenges and strategies. Aging $\mathcal{E}$ Mental Health, 12, 1, $5^{-1} 3$.

Accepted 24 November 2017 ; first published online I I January 2018

Address for correspondence:

Christine Ceci,

Faculty of Nursing, University of Alberta, Level 3,

Edmonton Clinic Health Academy,

Edmonton, Alberta, Canada T6 G 1 C9

E-mail: christine.ceci@ualberta.ca 